\title{
Influence of using nanoobjects as filler on functionality-based energy use of nanocomposites
}

\author{
A. L. Roes $\cdot$ L. B. Tabak $\cdot$ L. Shen $\cdot$ \\ E. Nieuwlaar $\cdot$ M. K. Patel
}

Received: 29 July 2009/ Accepted: 23 November 2009/Published online: 4 December 2009

(C) Springer Science+Business Media B.V. 2009

\begin{abstract}
The goal of our study was to investigate the potential benefits of reinforcing polymer matrices with nanoobjects for structural applications by looking at both the mechanical properties and environmental impacts. For determining the mechanical properties, we applied the material indices defined by Ashby for stiffness and strength. For the calculation of environmental impacts, we applied the life cycle assessment methodology, focusing on nonrenewable energy use (NREU). NREU has shown to be a good indicator also for other environmental impacts. We then divided the NREU by the appropriate Ashby index to obtain the 'functionality-based NREU'. We studied 23 different nanocomposites, based on thermoplastic and thermosetting polymer matrices and organophilic montmorillonite, silica, carbon nanotubes (single-walled and multiwalled) and calcium carbonate as filler. For 17 of these, we saw a decrease of the functionality-based NREU with increasing filler content. We draw the conclusion that the use of nanoobjects as filler can have benefits from both an environmental point of view and with respect to mechanical properties.
\end{abstract}

A. L. Roes $(\bowtie) \cdot$ L. B. Tabak · L. Shen ·

E. Nieuwlaar · M. K. Patel

Department of Science, Technology and Society,

Utrecht University, Copernicus Institute,

Heidelberglaan 2, 3584 CS Utrecht, The Netherlands

e-mail: a.1.roes@uu.nl
Keywords Mechanical properties . Nanocomposites · Nanoobjects ·

Non-renewable energy use $\cdot$ Polymers

\section{Introduction}

The mechanical properties of polymers can be improved by adding fillers. A wide range of fillers have been available for years, including glass fiber, carbon black, and natural fiber. Fillers with at least one dimension in the order of $1-10 \mathrm{~nm}$ are referred to as nanoobjects (comprising nanoparticles that are nanoscale at three external dimensions; nanofibers that are nanoscale in two external dimensions; and nanoplates that are nanoscale on one external dimension). Examples are layered silicates (nanoplate), carbon nanotubes (nanofiber), and silica (nanoparticle). The use of nanoobjects for reinforcement of polymers is a new technology which faces high expectations since it has shown to improve the mechanical properties significantly. A very common layered silicate nanoobject is montmorillonite. Polymers blended with montmorillonite have improved mechanical and thermal properties, gas permeability resistance, and fire retardancy (Ahmadi et al. 2004).

The mechanical properties are important factors for material choice in a specific application. Other important factors are the other material properties (e.g. impact strength, sensitivity to water and other compounds, and antistatic properties), the costs of the 
material, and health and safety issues. However, with growing emphasis on sustainable development, the environmental performance of a material becomes increasingly important. Bio-based polymers are rapidly emerging on the market, because they are expected to have less impact on the environment by not using a petrochemical feedstock. Some of these polymers, however, lack the performance of many petrochemical polymers. The use of nanoscale fillers could solve this problem by improving the mechanical properties. The use of nanoobjects to reinforce plastics is referred to as nanotechnology and can improve the mechanical properties of both bio-based and petrochemical polymers. The improved mechanical properties could allow a reduction in the amount of material needed for an application (such as car panels or packaging film), as was shown previously (Roes et al. 2007). If improved properties allow a reduction in material use, this might lead to a reduction in environmental impacts. However, the production and waste management of the nanoobjects could be accompanied by additional environmental impacts. It would therefore be very useful to have an indicator that addresses both the environmental performance of a material and its mechanical properties. In this study, we present and apply such an indicator: the 'functionality-based environmental impact' focusing on non-renewable energy use (NREU). Life cycle assessment (LCA) is a methodology to assess the environmental impacts of a product throughout its life cycle (International Standards Organisation 2006b). It is therefore a good tool for assessing the environmental performance of a material. For the assessment of mechanical properties, we will use the material indices developed by Ashby (2005) for stiffness and strength (see section “Approach”).

The method will be used to assess the potential benefits of using nanoobjects as filler in polymers compared to unfilled (neat) polymers or conventionally filled polymers. To this end, the NREU for making the nanoobjects needs to be determined as well. In this paper, we will discuss this for organophilic montmorillonite, silica and carbon nanotubes, based on published data and own estimates (see section "Environmental assessment of nanoobjects"). Next, we will determine the NREU and mechanical properties of 23 different nanocomposites (based on both petrochemical and bio-based thermoplastics and thermosets). As nanoscale fillers we use organophilic montmorillonite, silica, carbon nanotubes (singlewalled and multiwalled), and calcium carbonate $\left(\mathrm{CaCO}_{3}\right)$. An overview of the nanocomposites studied in this paper is given in Table 1. The choice of these nanocomposites aims to cover the most important polymers (based on global production volumes) and is also determined by the availability of suitable studies on both production methods and mechanical properties. For all nanocomposites, the functionalitybased environmental impact is determined for different loads (including zero load) of filler. For PP-MMT, PHB-MMT, and NR-MMT, a comparison with conventionally filled material is made as well, as can be seen from Table 1 .

In the section "Methodology", the methodology of this study is explained ("Approach"), together with an inventory analysis and impact assessments for organophilic montmorillonite, silica, and carbon nanotubes ("Environmental assessment of nanoobjects"). In the section "Results", the results are presented and they are discussed in the section "Discussion". We present our conclusions in the section "Conclusion".

\section{Methodology}

\section{Approach}

For the assessment of the environmental impacts, we used the LCA methodology, as it has been standardized by the International Standards Organization (goal definition and scoping, inventory analysis, impacts assessment, life cycle interpretation) (International Standards Organisation 2006a). We determined the environmental performance on a cradle-tograve basis. This means that we took into account all stages from raw materials extraction to waste management. We assume that nanocomposites are burned in a municipal waste incinerator and that for each gigajoule of waste $0.106 \mathrm{GJ}$ of electricity and 0.223 GJ of heat is regained ${ }^{1}$ (Reimann 2006; Reimann DO, CEWEP, Bamberg, Germany, personal communication, 2007). The use phase is assumed to be stationary, which means that no extra energy use or material use is assigned to it. As a proxy for

\footnotetext{
$\overline{1}$ Although not all municipal waste incinerators use combined heat and power generation, we assume this type as average values for Europe.
} 
Table 1 Composites studied in this paper

\begin{tabular}{|c|c|c|}
\hline & Abbreviation & Application $^{a}$ \\
\hline \multicolumn{3}{|l|}{ Nanocomposite-thermoplastic (petrochemical) } \\
\hline Nylon 6-montmorillonite & Nylon 6-MMT & Panel \\
\hline Nylon 66-montmorillonite & Nylon 66-MMT & Panel \\
\hline Polycarbonate-montmorillonite & PC-MMT & Panel \\
\hline Poly( $\varepsilon$-caprolactone)-montmorillonite & PCL-MMT & Panel \\
\hline Low-density polyethylene-montmorillonite & LDPE-MMT & Panel \\
\hline Linear low-density polyethylene-montmorillonite & LLDPE-MMT & Panel \\
\hline High-density polyethylene-montmorillonite & HDPE-MMT & Panel \\
\hline Cross-linked low-density polyethylene montmorillonite & XLDPE-MMT & Panel \\
\hline Polyethylene terephthalate-montmorillonite & PET-MMT & Panel \\
\hline Poly (methyl methacrylate)-multiwalled carbon nanotubes & PMMA-MWNT & Panel \\
\hline Polypropylene-montmorillonite & PP-MMT & Panel \\
\hline Polystyrene-singlewalled carbon nanotubes & PS-SWNT & Panel \\
\hline Poly(trimethylene terephthalate)-montmorillonite & PTT-MMT & Panel \\
\hline Polyurethane-montmorillonite & PU-MMT & Panel \\
\hline Polyvinyl chloride-montmorillonite & PVC-MMT & Tie \\
\hline Polyvinyl chloride-calcium carbonate & $\mathrm{PVC}-\mathrm{CaCO}_{3}$ & Tie \\
\hline \multicolumn{3}{|l|}{ Nanocomposite-thermoplastic (bio-based) } \\
\hline Poly(hydroxybutyrate)-montmorillonite & PHB-MMT & Panel \\
\hline Polylactic acid-pyrogenic silica & PLA-Si & Panel \\
\hline Polylactic acid-montmorillonite & PLA-MMT & Panel \\
\hline Thermoplastic starch-montmorillonite & TPS-MMT & Panel \\
\hline \multicolumn{3}{|l|}{ Nanocomposite-thermosets (petrochemical) } \\
\hline $\begin{array}{l}\text { Sulfonated ethylene-propylene-norbonene } \\
\text { terpolymer-single walled carbon nanotubes }\end{array}$ & EPDM-SWNT & Tie \\
\hline Epoxy-silica sol & Ep-Si & Panel \\
\hline \multicolumn{3}{|l|}{ Nanocomposite-thermosets (bio-based) } \\
\hline Natural rubber-montmorillonite & NR-MMT & Tie \\
\hline \multicolumn{3}{|l|}{ Conventionally filled material } \\
\hline Polypropylene-glass fiber & PP-GF & Panel \\
\hline Poly(hydroxybutyrate)-sugarcane bagasse & PHB-BGS & Panel \\
\hline Natural rubber-carbon black & NR-CB & Tie \\
\hline
\end{tabular}

a See section "Approach"

expressed by Ashby's material index (MI), which is a function of material properties such as the Young's modulus $(E)$, tensile strength $\left(\sigma_{\mathrm{f}}\right)$, and density $(\rho)$. Ashby developed equations for MI for different functional requirements, such as strength or stiffness. $^{2}$ The larger the value for MI is, the better the

\footnotetext{
$\overline{2}$ Apart from strength and stiffness, other important mechanical properties could be barrier properties and UV resistance. We limit ourselves to strength and stiffness because these properties are important for most applications of nanocomposites. Barrier properties are primarily important for packaging materials, while UV resistance is particularly needed for outdoor applications.
} 
mechanical properties of the product under consideration are and the less material is needed for a certain function. The material indices developed by Ashby are based on design that is 'stiffness-limited', 'strength-limited', 'vibration-limited', 'damage-tolerant', 'electro-mechanical', or 'thermal and thermomechanical'. Within each category, the appropriate function and constraints are chosen (functions could be, e.g., 'tie', 'shaft', 'beam', 'column', 'panel' or 'plate'; constraints could be, e.g., required specification of dimensions).

For the (nano-)composites with 'panel' as an application (Table 1), we assume a flat plate, which is stiffness-limited and loaded by bending. For such a plate (called 'panel'), Ashby defined the following material index (Eq. 1):

$\mathrm{MI}_{\text {panel }}=E^{1 / 3} / \rho\left(\right.$ unit: $\left.\mathrm{MPa}^{1 / 3} \cdot \mathrm{dm}^{3} \cdot \mathrm{kg}^{-1}\right)$

For the (nano-)composites with 'tie' as an application (Table 1), we assume that it will be applied in products that are strength-limited, such as films (the material should not break or tear apart). The stress applied to the material, trying to break it during use, is 'tie'. Ashby defined the following material index for such an application (Eq. 2):

$$
\mathrm{MI}_{\text {tie }}=\sigma_{\mathrm{f}} / \rho\left(\text { unit: } \mathrm{MPa} \cdot \mathrm{dm}^{3} \cdot \mathrm{kg}^{-1}\right)
$$

The functionality-based environmental impacts are now calculated as (Eq. 3):

Functionality based environmental impact

$$
=\frac{\text { Environmental impact }}{\text { Material index }}
$$

In case the 'Material index' is $\mathrm{MI}_{\text {panel, }}$, the unit is $\mathrm{MJ} \cdot \mathrm{kg} \cdot \mathrm{MPa}^{-1 / 3} \cdot \mathrm{dm}^{-3}$.

In case the 'Material index' is $\mathrm{MI}_{\text {tie }}$, the unit is $\mathrm{MJ} \cdot \mathrm{kg} \cdot \mathrm{MPa}^{-1} \cdot \mathrm{dm}^{-3}$.

To determine the environmental impacts of common polymers such as EPDM or polypropylene, data are readily available via databases such as Ecoinvent (2009) and PlasticsEurope (2009). For other materials, such as poly( $\varepsilon$-caprolactone) or tetraethoxysilane and Jeffamine D2000 (used in the production of epoxy-silica nanocomposite), we had to derive the impacts ourselves. This was done by analyzing the production of those materials (making use of chemical encyclopedias; Kirk-Othmer 1998; Ullmann's 2007; Wikipedia 2007) and estimating material and
Table 2 Environmental impacts of organophilic montmorillonite

\begin{tabular}{lll}
\hline Study & NREU (MJ/kg) & $\begin{array}{l}\text { GWP100 } \\
\left(\mathrm{kg} \mathrm{CO} \text { C }^{-\mathrm{eq}} / \mathrm{kg}\right)\end{array}$ \\
\hline Roes et al. (2007) & 69.7 & 3.55 \\
Joshi (2008) & 40.1 & 1.52 \\
\hline
\end{tabular}

energy requirements. Then, we used the Ecoinvent databases (available in SimaPro; PRé Consultants 2006) for completing the inventory analysis which is the basis of the impact assessment.

Environmental assessment of nanoobjects

Since the environmental impacts of the nanoobjects used as filler may contribute significantly to the environmental impacts of nanocomposites, we gathered information regarding their production and environmental impacts. For organophilic montmorillonite and carbon nanotubes, published studies exist on an environmental assessment. We will discuss these studies (sections "Impact assessment of organophilic montmorillonite" and "Impact assessment of carbon nanotubes"). For silica, environmental impacts have not yet been studied and will be estimated in this paper (section "Impact assessment of silica"). The environmental assessments will focus on NREU and impact on climate change. ${ }^{3}$

\section{Impact assessment of organophilic montmorillonite}

Two studies were found in which the production of organophilic montmorillonite is studied. In Roes et al. (2007), life cycle inventory data are presented and in Joshi (2008) environmental impacts are presented. Table 2 shows the NREU and GWP100 as obtained/calculated from each of these studies.

From Table 2 it appears that the environmental impacts in the study by Joshi (2008) are lower than in the study by Roes et al. (2007). Since both studies are based on personal communication with a manufacturer and the data sources of Joshi (2008) cannot, as

\footnotetext{
${ }_{3}$ Impact on climate change is defined as the Global Warming Potential in the next 100 years $\left(\mathrm{GWP}_{100}\right)$. The methodology is described by the Intergovernmental Panel on Climate Change (IPCC 2007).
} 
such, be traced back, we use own values from earlier research (from Roes et al. 2007) in the calculations in this study. However, the uncertainty will be addressed in the uncertainty analysis in the section "Uncertainties".

\section{Impact assessment of silica}

For silica, no published studies on environmental impacts were found. Therefore, we will present both the inventory data and the environmental impacts of silica.

Nanoscale silica $\left(\mathrm{SiO}_{2}\right)$ is manufactured at industrial scale in four types: silica sol (i.e. colloidal silica), silica gel, precipitated silica, and pyrogenic silica. These types differ in the way the particles are agglomerated. Figure 1 shows the typical structures of the four types of silica. Using data from a report by the European Commission (2007) and the stoichiometry of the reactions to produce the silica, an inventory analysis was made from which environmental impacts were calculated. Tables 3 and 4 show the material and energy requirements for the production of silica sol,

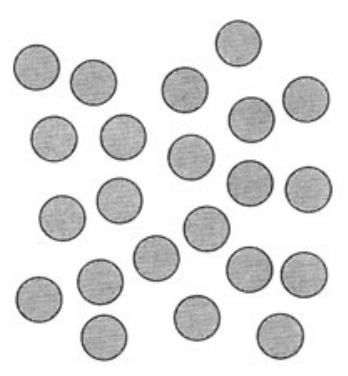

(a)

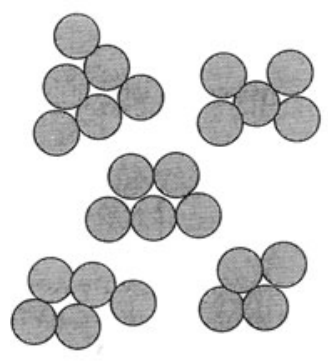

(c)

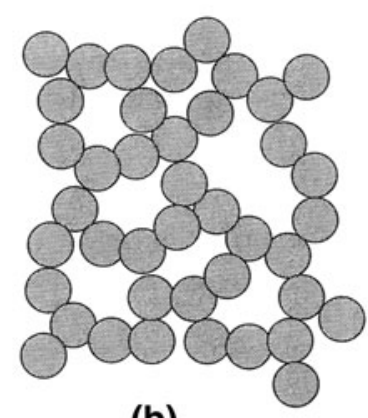

(b)

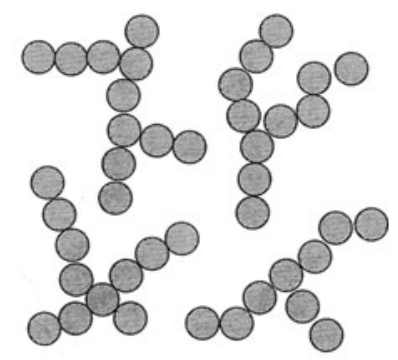

(d)
Fig. 1 Different forms of commercially important amorphous silica: a sol, b gel, c precipitate, and d pyrogenic (Patterson 1998). Reproduced with permission of John Wiley \& Sons, Inc. silica gel, precipitated silica, and pyrogenic silica. The material requirements for silica sol, silica gel, and precipitated silica are essentially identical. Differences concern only the manufacturing process but not the material requirements. Silica gel and precipitated silica, however, are sold as dry powder, while silica sol is sold as a suspension. Natural gas is used for drying of the silica gel and precipitated silica. For silica sol, natural gas is used to increase the concentration directly after manufacturing from 10 to $20 \%$. According to the report by the European Commission (2007), natural gas use for drying silica gel and precipitated silica is $15-24 \mathrm{MJ} / \mathrm{kg}$. ${ }^{4}$ Since no data are reported for silica sol, a producer was contacted (Barthel H, Wacker Chemie AG, München Germany, personal communication, 2008), who estimated natural gas use to be $36 \mathrm{MJ} / \mathrm{kg}$. Because silica sol is not completely dried, it is questionable whether energy use for silica sol is so much higher than for silica gel and precipitated silica. A calculation based on heat of evaporation of water (for increasing the concentration from 10 to $20 \%$ solids) yields $11 \mathrm{MJ} / \mathrm{kg}$ silica sol. Given this uncertainty, if the inventory data from Table 3 are used for any calculation, both values (11 and $36 \mathrm{MJ} / \mathrm{kg}$ ) should be used to arrive at a 'best estimate' and a 'worst estimate' (see Table 4; the same holds for the value range for drying of silica gel and precipitated silica [15-24 MJ/kg] and the energy use for pyrogenic silica [15-18 MJ/kg]).

All processes yield more than one product (see Tables 3 and 4). We therefore applied the system expansion method (International Standards Organization 2000), thereby assuming that the co-products would have been manufactured according to the dominating industrial processes. In Table 5, the environmental impacts are shown of the different silica types.

\section{Impact assessment of carbon nanotubes}

For the environmental assessment of carbon nanotubes, two studies have been published: Kushnir and Sandén (2008) and Healy et al. (2008). These studies

\footnotetext{
4 Also for pyrogenic silica natural gas is consumed. It is used for heating hydrogen gas and combustion air, for the evaporation of silicon tetrachloride, as well as for removing residual hydrochloride from the silica surface.
} 
Table 3 Material and energy requirements and emissions for the production of silica gel, precipitated silica and silica sol (European Commission 2007)

\begin{tabular}{|c|c|c|}
\hline & $\begin{array}{l}\text { Amount for } \\
\text { silica gel and } \\
\text { precipitated silica }\end{array}$ & $\begin{array}{l}\text { Amount for } \\
\text { silica sol }\end{array}$ \\
\hline \multicolumn{3}{|l|}{ Input } \\
\hline Sodium silicate & $3.9 \mathrm{~kg}$ & $3.9 \mathrm{~kg}$ \\
\hline Sulfuric acid & $0.66 \mathrm{~kg}$ & $0.66 \mathrm{~kg}$ \\
\hline $\begin{array}{l}\text { Natural gas (for silica gel } \\
\text { and precipitated silica) }\end{array}$ & $15-24 \mathrm{MJ}$ & $11-36 \mathrm{MJ}$ \\
\hline Water & $40 \mathrm{~kg}$ & $40 \mathrm{~kg}$ \\
\hline \multicolumn{3}{|l|}{ Output } \\
\hline $\begin{array}{l}\text { Silica gel/precipitated } \\
\text { silica/silica sol }\end{array}$ & $1 \mathrm{~kg}$ & $1 \mathrm{~kg}$ \\
\hline Sodium sulphate & $0.96 \mathrm{~kg}$ & $0.96 \mathrm{~kg}$ \\
\hline \multicolumn{3}{|l|}{ Emissions to air } \\
\hline Particulates & $0.0013 \mathrm{~kg}$ & $0.0013 \mathrm{~kg}$ \\
\hline \multicolumn{3}{|l|}{ Emissions to water } \\
\hline Waste water & $35 \mathrm{~kg}$ & $35 \mathrm{~kg}$ \\
\hline
\end{tabular}

Table 4 Material and energy requirements and emissions to air for the production of pyrogenic silica (European Commission 2007)

\begin{tabular}{ll}
\hline & Amount \\
\hline Input & \\
Silicon tetrachloride & $2.83 \mathrm{~kg}$ \\
Hydrogen & $0.067 \mathrm{~kg}$ \\
Natural gas & $15-18 \mathrm{MJ}$ \\
Output & \\
Pyrogenic silica & $1 \mathrm{~kg}$ \\
Hydrochloric acid & $2.43 \mathrm{~kg}$ \\
Emissions to air & \\
Particulates & $0.0003 \mathrm{~kg}$ \\
$\mathrm{NO}_{x}$ & $0.0001 \mathrm{~kg}$ \\
$\mathrm{Cl}_{2}$ & $0.00005 \mathrm{~kg}$ \\
$\mathrm{HCl}$ & $0.00001 \mathrm{~kg}$ \\
$\mathrm{VOC}^{\mathrm{CO}}{ }_{2}$ & $0.0003 \mathrm{~kg}$ \\
\hline
\end{tabular}

cover several production processes ${ }^{5}$ for single-walled carbon nanotubes (SWNT) and multiwalled carbon nanotubes (MWNT) and are based on publicly

\footnotetext{
$\overline{5}$ Included processes are fluidized bed and floating catalyst chemical vapor deposition, high-pressure carbon monoxide process, electric arc process, laser ablation process, and solar furnace process.
}

Table 5 Environmental impacts caused by the production of silica

\begin{tabular}{llllll}
\hline Silica type & \multicolumn{2}{l}{ NREU $(\mathrm{MJ} / \mathrm{kg})$} & & \multicolumn{2}{l}{$\begin{array}{l}\mathrm{GWP100} \\
\left(\mathrm{kg} \mathrm{CO} \mathrm{CO}_{2} \text {-eq/kg }\right)\end{array}$} \\
\cline { 2 - 3 } \cline { 6 - 6 } & $\begin{array}{l}\text { Low } \\
\text { estimate }\end{array}$ & $\begin{array}{l}\text { High } \\
\text { estimate }\end{array}$ & & $\begin{array}{l}\text { Low } \\
\text { estimate }\end{array}$ & $\begin{array}{l}\text { High } \\
\text { estimate }\end{array}$ \\
\hline Silica sol & 61.0 & 92.2 & & 3.20 & 4.98 \\
Silica gel & 66.0 & 77.3 & & 3.48 & 4.12 \\
Precipitated silica & 66.0 & 77.3 & & 3.48 & 4.12 \\
Pyrogenic silica & 63.7 & 67.4 & & 4.57 & 4.78 \\
\hline
\end{tabular}

available data and on information provided by manufacturers. The results in the two studies differ enormously, however. For example, regarding electricity use in the high-pressure carbon monoxide process (HiPco), Kushnir and Sandén have estimated $6 \mathrm{GJ}_{\mathrm{e}} / \mathrm{kg}$, whereas Healy et al. arrive at $145 \mathrm{GJ}_{\mathrm{e}} / \mathrm{kg}$. This reflects the high uncertainty in process data as available to researchers.

In 2009, Bayer Material Science (BMS) AG (Leverkusen, Germany) announced to set up the industrial production of carbon nanotubes in a plant with a capacity of 3,000 tonnes per year. The applied process is fluidized-bed chemical vapour deposition (for information, see www.baytubes.com). Data for this process should best reflect large-scale industrial practice. In order to obtain realistic process data of this process, the head of Bayer's Working Group Nanotechnology was contacted (Krüger P, Bayer Material Science, Leverkusen, Germany, personal communication, 2009). Unfortunately, due to strict confidentiality regulations, it was not possible to disclose any information regarding the process in their factory. However, process data for the fluidized bed chemical vapour deposition (baseline case), published by Kushnir and Sandén, were confirmed to be a reasonable estimate for a large-scale plant (with small-scale plants having an energy use that can be up to 1,000 times larger). These data hold for SWNT, while BMS produces exclusively multi-walled carbon nanotubes (MWNT). The structure, production process, and applications for SWNT and MWNT are totally different. According to personal communication with Bayer, the energy use of MWNT production is roughly $10 \%$ of the energy use of SWNT and it is in the worst case somewhere in the order of magnitude of the energy use of carbon black production. 
Table 6 Energy use in the production of SWNT and MWNT

\begin{tabular}{|c|c|c|c|}
\hline & $\begin{array}{l}\text { Thermal } \\
\text { energy }\left(\mathrm{MJ}_{\mathrm{th}} / \mathrm{kg}\right)\end{array}$ & $\begin{array}{l}\text { Electric energy } \\
\left(\mathrm{MJ}_{\mathrm{e}} / \mathrm{kg}\right)\end{array}$ & Source \\
\hline SWNT & 328 & 626 & Kushnir and Sandén (2008) \\
\hline MWNT & 32.8 & 62.6 & $\begin{array}{l}\text { Krüger P, Bayer Material Science, } \\
\text { Leverkusen, Germany, personal } \\
\text { communication, } 2009\end{array}$ \\
\hline
\end{tabular}

Table 7 Environmental impacts caused by the production of carbon nanotubes

\begin{tabular}{lll}
\hline & NREU $(\mathrm{MJ} / \mathrm{kg})$ & $\mathrm{GWP100}\left(\mathrm{kg} \mathrm{CO} \mathrm{CO}_{2}\right.$ eq $\left./ \mathrm{kg}\right)$ \\
\hline SWNT & 2145 & 110 \\
MWNT & 215 & 11 \\
\hline
\end{tabular}

The energy use for SWNT and MWNT production as estimated on the basis of this information is listed in Table 6.

The production of carbon black uses $9 \mathrm{MJ} / \mathrm{kg}$ natural gas and $79 \mathrm{MJ} / \mathrm{kg}$ oil (power use is not mentioned) (Ullmann's 2007). This is $88 \mathrm{MJ}$ final energy. The production of MWNT uses 95.4 MJ final energy. This roughly supports the data for MWNT as derived from Kushnir and Sandén and personal communication with Bayer. The environmental impacts of SWNT and MWNT are listed in Table 7.

\section{Results}

NREU of the nanocomposites and unfilled or conventionally filled materials was determined with help of the Ecoinvent databases. The Ashby material indices were determined, based on the Young's modulus, the tensile strength and the density. From the analyses, it appeared that there was a large variation in mechanical properties as a consequence of the methods applied for nanocomposite preparation. These differences could be the result of, for example, the method of mixing the nanoscale filler and the polymer matrix (solvent casting or extrusion, different temperatures, different equipment), or the type of surfactant and/or compatibilizer used to enhance exfoliation of the filler in the matrix. However, in order to fully determine the potential benefits of using nanoobjects to reinforce polymers, we assume best available technology. Therefore, if different results were obtained with data applying different techniques, we present only the best case. But in order to get a better understanding of the possible reasons for differences, we present for one nanocomposite (LDPE-MMT) all results for various techniques and we explain the differences. The results are shown in Figs. $2 \mathrm{a}-\mathrm{d}$ and $3 \mathrm{a}-\mathrm{c}$. Note that the value ranges are quite different in Figs. $2 a$ and $2 b-d$ and in $3 \mathrm{~b}$ and $3 \mathrm{a}, \mathrm{c}$. The literature sources from which the data for the analyses were taken are listed in Table 8.

The results show that for PC-MMT, LLDPE-MMT, PTT-MMT, HDPE-MMT, TPS-MMT, Ep-Si, PCLMMT, PU-MMT, XLDPE-MMT, LDPE-MMT, Nylon 66-MMT, PET-MMT, Nylon 6-MMT, PLASi, PMMA-MWNT, ${ }^{6}$ NR-MMT, EPDM-SWNT and PVC-MMT, the functionality-based NREU decreases with increasing filler content (this is a desirable outcome). It is reflected by a negative slope of the plots. PP-MMT has slightly higher functionality based NREU than PP-GF (see Fig. 2a). Also, the PHB composites using a nanoobject (MMT) cause higher functionality-based environmental impacts than the PHB composite using a natural fiber (BGS). Nanocomposites for which the functionality-based NREU increases with increasing filler content (positive slope of the plot) are PP-MMT, PHB-MMT, PS-SWNT, PLA-MMT and PVC-CaCO 3 (no desirable outcome).

As explained above (see Eq. 3), the functionalitybased environmental impact depends, on the one hand, on the environmental impact (NREU) and, on the other hand, on the Ashby material index $\left(\mathrm{MI}_{\mathrm{panel}}, \mathrm{MI}_{\mathrm{tie}}\right)$. Only if the addition of a filler causes an increase in the material index that is larger than the increase in environmental impact, caused by the production of the nanoparticles and their dispersion in the polymer matrix, the functionality-based environmental impact will decrease with increasing filler content. For functionality-based NREU, this is the case for the nanocomposites that show a negative slope in Figs. 2 and 3.

\footnotetext{
$\overline{{ }^{6}}$ The slope of this line is negative, albeit minor.
} 

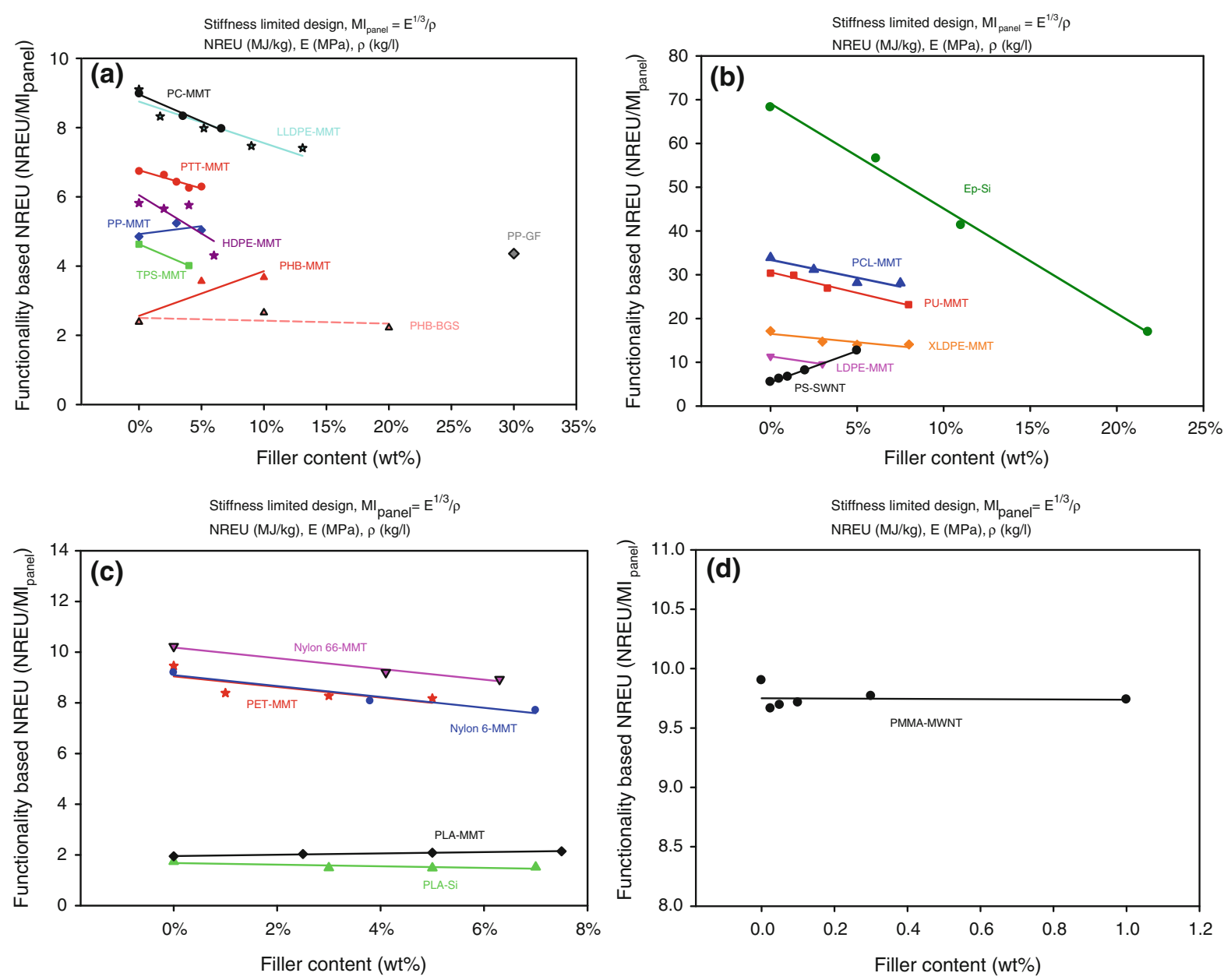

Fig. 2 a-d Functionality-based NREU of panels with stiffness-limited design

For PP-MMT and PLA-MMT, PS-SWNT, the material index increases with increasing filler content, but the increase of NREU is larger, caused by the extra impacts of adding nanoobjects, resulting in an increasing functionality-based NREU. Especially the use of carbon nanotubes in the PS-SWNT nanocomposites causes a large increase in NREU, due to the very high environmental impacts of carbon nanotube production (see Table 7). The reason that the PHB nanocomposite using MMT has increasing functionality-based NREU (Fig. 2a) is because, on one hand, there is a decrease in material properties and, on the other hand, the environmental impacts increase as a result of the production and adding of the nanoobjects.

Natural rubber filled with $10 \%$ nanoclay (i.e. organophilic MMT) causes lower functionality-based environmental impacts than unfilled natural rubber
(Fig. 3a). If other fillers are used (carbon black or unmodified clay), there are no benefits at all. The reason is that NR-10MMT has a very high tensile strength (105 MPa) compared to the other samples. The negative values for functionality-based NREU are caused by energy credits in the waste stage and by the fact that NREU of natural rubber is low, since it is a bio-based material.

PVC-CaCO 3 has a decreasing NREU (per kg) with increasing filler content, but the mechanical properties are bad and decrease faster than the NREU (per $\mathrm{kg}$; see Fig. 3c). The resulting functionality-based NREU therefore increases.

The result for PVC-MMT is somewhat irregular; for small additions of a nanoscale filler, the functionalitybased NREU decreases, but starts increasing if more filler is used. This is caused by the fact that the use of 

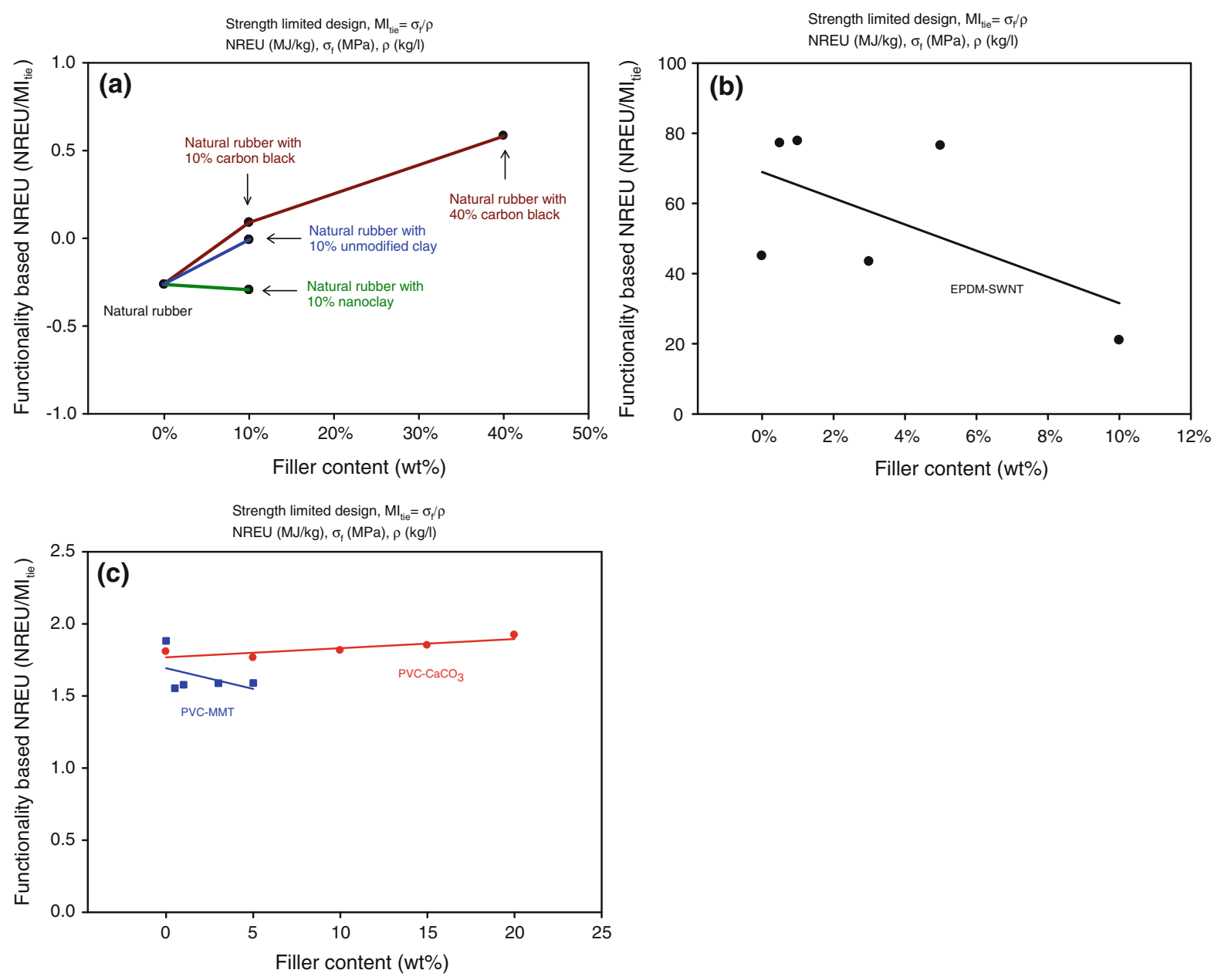

Fig. 3 a Functionality-based NREU of a natural rubber based tie with strength-limited design. b Functionality-based NREU of an EPDM-SWNT tie with strength-limited design.

c Functionality-based NREU of a PVC-MMT and PVC-CaCO tie with strength-limited design

MMT improves the tensile strength drastically already at low content (from $51 \mathrm{MPa}$ for pure PVC to $62 \mathrm{MPa}$ at $0.5 \% \mathrm{MMT}$ ), but if more filler is used, the tensile strength (and the material index) starts decreasing. A similar pattern is observed for PMMA-MWNT.

\section{Discussion}

Analysis of factors influencing mechanical properties

In order to optimize the mechanical properties of nanocomposites, it is important that the particles and the polymer matrix are optimally mixed and bound to

each other. Often, the fabrication of polymer nanocomposites is hindered by the tendency of the nanoobjects to form agglomerates. The presence of agglomerates in a polymer nanocomposite can negate the advantages of the nanoobject filler because (a) under load there may be slippage within the agglomerate, (b) it reduces the surface area for the interaction between the nanoobjects and the polymer and (c) it can initiate fracture at the agglomerate sites (West and Malhotra 2006). To prevent agglomeration, several methods can be applied. West and Malhotra (2006) report a new technique applying ultrasonic cavitation using a high-intensity ultrasonic processor. The ultrasonic probe creates pressure waves, which destroy agglomerates. Another way to achieve 
Table 8 Data sources used in the assessment of mechanical properties

\begin{tabular}{|c|c|}
\hline & Reference \\
\hline \multicolumn{2}{|l|}{ Nanocomposite-thermoplastic (petrochemical) } \\
\hline Nylon 6-montmorillonite & Chavarria and Paul (2004) \\
\hline Nylon 66-montmorillonite & Chavarria and Paul (2004) \\
\hline Polycarbonate-montmorillonite & Yoon et al. (2003) \\
\hline Poly( $\varepsilon$-caprolactone)-montmorillonite & Luduena et al. (2007) \\
\hline \multicolumn{2}{|l|}{ Low-density polyethylene-montmorillonite } \\
\hline $\mathrm{Na}^{+}$, Cloisite B, Cloisite C, Cloisite 30B, Cloisite D & Malucelli et al. (2007) \\
\hline Triclay & Zhang et al. (2006a) \\
\hline Lauryl clay & Zhang et al. (2005a) \\
\hline Triclay II & Zhang et al. (2006b) \\
\hline Octadecylamine (ODA) & Morawiec et al. (2005) \\
\hline Linear low-density polyethylene-montmorillonite & Hotta and Paul (2004) \\
\hline High-density polyethylene-montmorillonite & Tjong and Bao (2007) \\
\hline Cross-linked low-density polyethylene montmorillonite & Rezanejad and Mehrdad (2007) \\
\hline Polyethylene terephthalate-montmorillonite & Wang et al. (2006) \\
\hline $\begin{array}{l}\text { Poly (methyl methacrylate)-multiwalled } \\
\text { carbon nanotubes }\end{array}$ & Lee et al. (2006) \\
\hline Polypropylene-montmorillonite & $\begin{array}{l}\text { Estimate from Matweb (2008) } \\
\text { and Svoboda et al. (2002) }\end{array}$ \\
\hline Polystyrene-singlewalled carbon nanotubes & Nayak et al. (2007) \\
\hline Poly(trimethylene terephthalate)-montmorillonite & Drown et al. (2007) \\
\hline Polyurethane-montmorillonite & Chavarria and Paul (2006) \\
\hline Polyvinyl chloride-montmorillonite & Wan et al. (2003) \\
\hline Polyvinyl chloride-calcium carbonate & Zhang et al. (2005b) \\
\hline \multicolumn{2}{|l|}{ Nanocomposite-thermoplastic (bio-based) } \\
\hline Poly(hydroxybutyrate)-montmorillonite & Pietrini et al. (2007) \\
\hline Polylactic acid-pyrogenic silica & Halimi and Gerard (2008) \\
\hline Polylactic acid-montmorillonite & Jiang et al. (2007) \\
\hline Thermoplastic starch-montmorillonite & Avella et al. (2005) \\
\hline \multicolumn{2}{|l|}{ Nanocomposite-thermosets (petrochemical) } \\
\hline $\begin{array}{l}\text { Sulfonated ethylene-propylene-norbonene } \\
\text { terpolymer-singlewalled carbon nanotubes }\end{array}$ & $\begin{array}{l}\text { López-Manchado MA, Institute of } \\
\text { Polymer Science and Technology, } \\
\text { CSIC, Madrid, Spain, personal } \\
\text { communication, } 2007\end{array}$ \\
\hline Epoxy-silica sol & Matějka et al. (2000) \\
\hline \multicolumn{2}{|l|}{ Nanocomposite-thermosets (bio-based) } \\
\hline Natural rubber-montmorillonite & Arroyo et al. (2003) \\
\hline \multicolumn{2}{|l|}{ Conventionally filled material } \\
\hline Polypropylene-glass fiber & Matweb (2008), Qiu et al. (1999) \\
\hline Poly(hydroxybutyrate)-sugarcane bagasse & Pietrini et al. (2007) \\
\hline Natural rubber-carbon black & Arroyo et al. (2003) \\
\hline
\end{tabular}

optimal dispersion is by treating the surface of the nanoobjects. This can be done in various ways, which are linked to the physical and chemical properties of both the nanoobject and the polymer. Different conditions give different results (also for the functionality-based environmental impacts), so it is important to create optimal conditions. We will discuss the influence of various conditions on the 


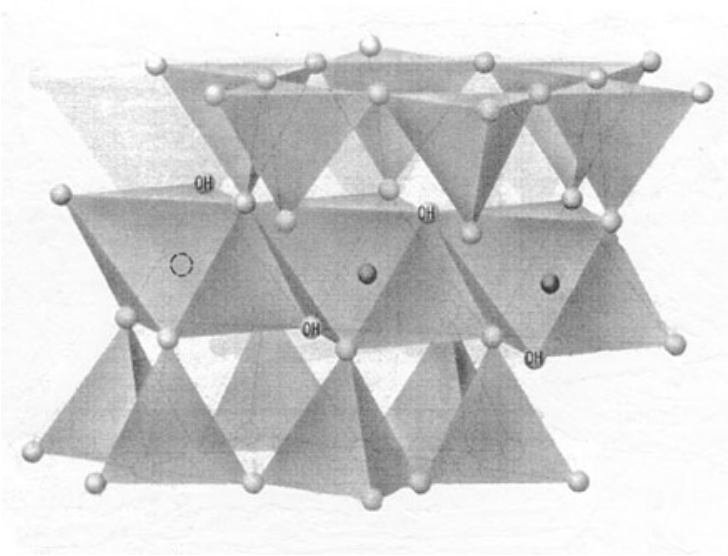

Fig. 4 The layered structure of montmorillonite (Nanocor 2008). Reproduced with permission of Nanocor, Inc.

basis of LDPE-MMT as an example. This nanocomposite uses montmorillonite as filler. Montmorillonite is a type of clay of which the particles are plateshaped, which form layers. An example of the layered structure is shown in Fig. 4. The gap between the layers is called the interlayer or the gallery. The distance between the clay layers is defined as the interlayer spacing, basal spacing or $d$-spacing. The galleries are occupied by cations such as $\mathrm{Na}^{+}$.

The material properties of a nanocomposite are maximally improved when the layers are randomly distributed in the polymer matrix. This means that all individual layers are separated and there is maximal contact with the matrix. This is called exfoliation or delamination. In some cases, the clay is only partly separated and several layers still stick together, but with the polymer in between them. This is called intercalation. Achievement of full exfoliation is difficult because montmorillonite is hydrophilic. Most polymers, especially thermoplastics, are mainly hydrophobic. The surface of the clay can be modified in order to decrease the surface tension. The surface can be modified by surfactants that exchange the positively charged inorganic ions in the interlayer distance for positively charged organic ions. These surfactants make the surface of the clay more organophilic. They also increase the interlayer distance. As a consequence, the clay is better miscible with the polymer matrix. If the surfactant molecules are not sufficient for full exfoliation, a compatibilizer can be added as well. This is a molecule which is compatible with the surfactant and the polymer matrix. The most widely applied compatibilizer is maleic anhydride grafted polymer (Hotta and Paul 2004).

In the example of LDPE-MMT nanocomposite, various surfactants and/or compatibilizers are used, leading to different results (for references, see Table 8). An overview is given in Table 9. The results for functionality based NREU are shown in Fig. 5.

Figure 5 shows that the starting point for neat LDPE ( $0 \%$ filler) is different for some of the samples. Although the NREU can be assumed to be identical for all unfilled LDPE samples, there is some variation in Young's modulus as it is reported by the sources from which the mechanical properties are taken (measuring mechanical properties is a very sensitive process that can give different results when different equipment is used and for different samples, even if it is the same material). This results in different material indices and thus different functionality-based NREU. Nevertheless, the figure shows that all Cloisite nanocomposites and a nanocomposite with untreated clay (MMT- $\mathrm{Na}^{+}$) have a decrease in functionalitybased NREU with increasing filler content. For MMTTriclay, MMT-Lauryl Clay and MMT-ODA, the functionality-based NREU increases.

The negative results for MMT-Triclay, MMTLauryl clay and MMT-ODA are a result of a strong increase of NREU with increasing filler content, while the material index remains more or less equal (MMTTriclay II) or decreases (MMT-Triclay, -Lauryl clay and -ODA). The increase in NREU is a result of extra impacts of the incorporation of nanoobjects compared to unfilled LDPE. The fact that the material indices of LDPE-MMT-Triclay (and II) and LDPE-MMT-Lauryl clay do not improve with increasing filler content could be a result of the fact that the oligomeric molecules by which the clay is modified are too large to penetrate into the interlaying spacing, which makes exfoliation difficult.

When ODA is used for treatment of MMT, the Young's modulus of the nanocomposite increases slightly, but the increase in density is stronger, resulting in a decrease of the material index (see Eq. 1). As a consequence, the functionality-based NREU increases with rising filler content.

For the Cloisite clays, the results are better. Table 10 gives details of the results. It shows that the material indices of all Cloisite nanocomposites improve compared to unfilled LDPE. Only for LDPE with untreated clay there is no improvement. 
Table 9 Descriptions of the various filler types used in LDPE nanocomposite

\begin{tabular}{ll}
\hline Name of filler $^{\mathrm{a}}$ & Description \\
\hline MMT-Na $^{+}$ & Untreated clay \\
MMT-Cloisite B & MMT-Na $^{+}$that is ion exchanged with octadecylammonium chloride \\
MMT-Cloisite C & MMT-Cloisite B that is ion exchanged with octadecylamine \\
MMT-Cloisite 30B & MMT treated with methyl, tallow, bis-2-hydroxyethyl, quaternary ammonium \\
& chloride (MT2EtOH), having hydroxyl groups \\
MMT-Cloisite D & MMT-Cloisite 30B treated with octadecylamine \\
MMT-Triclay & styrene and vinylbenzyl chloride \\
& MMT that is oligomerically modified by a copolymer of lauryl acrylate and vinylbenzyl chloride \\
MMT-Lauryl Clay & Octadecyl amine modified Nanomer I30P from Nanocor (USA). Maleic anhydride grafted \\
MMT-ODA & polyethylene is used as a compatibilizer \\
\hline
\end{tabular}

${ }^{\text {a }}$ Only in MMT-ODA a compatibilizer is used. In all other fillers only surfactants are used

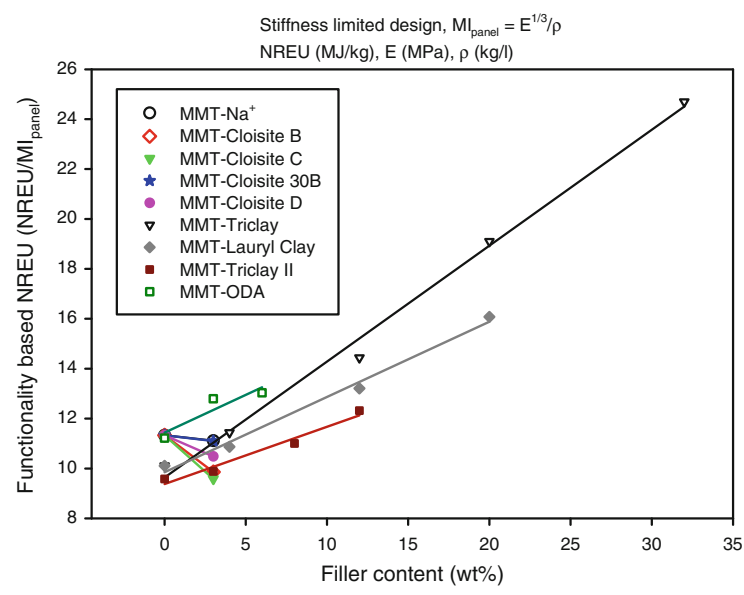

Fig. 5 Functionality-based NREU of LDPE-MMT panels with stiffness-limited design [Note: The choice of stiffness limited design ('Panel') for LDPE nanocomposites could be questioned, since LDPE is primarily used for films and sheets (Freudenstein 2007), for which the design would normally be strength limited ('Tie'). However, LDPE could also be used for applications which should be stiff. In fact, in the studied articles on LDPE nanocomposites, the Young's modulus (indicating stiffness) was reported for all LDPE-MMT alternatives, while tensile strength (indicating strength) was reported for only a limited number of alternatives, making it impossible to perform an assessment for 'Tie' for all LDPE nanocomposites.] (MMT-Na ${ }^{+}$is hidden beneath MMT-Cloisite 30B)

However, for all Cloisite nanocomposites, the NREU in MJ per $\mathrm{kg}$ is higher compared to neat LDPE while for LDPE with untreated clay $\left(\mathrm{MMT}-\mathrm{Na}^{+}\right)$it is slightly lower.

The best results are for LDPE-MMT-Cloisite C followed by LDPE-MMT-Cloisite B. All Cloisite clays use surfactants to make the clay more hydrophobic and/or to increase the interlayer distance. The surfactants occupy the space between the platelets and due to their large size the distance between the platelets is increased. The large alkyl tales make the clay more hydrophobic. In the case of Cloisite B, the interlayer spacing is increased due to the ion exchange of $\mathrm{Na}^{+}$with octadecylammonium chloride. In Cloisite $\mathrm{C}$, the interlayer spacing is increased even more due to extra ion exchange with octadecylamine. This is shown in Fig. 6. This increase in interlayer distance results in good exfoliation and thus in an improvement of the mechanical properties. The reason for the slightly smaller material indices of LDPE-MMT-Cloisite 30B and LDPEMMT-Cloisite D could be the presence of hydroxyethyl groups, which are hydrophilic and therefore less mixable with the hydrophobic polymer matrix.

\section{Extrusion}

Polymers that are blended with color pigments or additives are often sold on the market as 'masterbatches'. Such a masterbatch contains a high concentration of the additive and can be diluted or mixed with pure polymers and/or other masterbatches for further processing. Nanocomposites have not yet been produced on a large scale and we are not aware of commercial masterbatches for nanocomposites. However, masterbatches have been used in the laboratory scale production of PP-MMT and LDPEMMT-ODA, both of which use a compatibilizer (maleic anhydride) to graft the polymer matrix. The masterbatches consist of the grafted polymer, some 
Table 10 Results for neat LDPE, LDPE with untreated clay and LDPE with Cloisite clays

\begin{tabular}{lllll}
\hline $\begin{array}{l}\text { Type of LDPE } \\
\text { nanocomposite }\end{array}$ & $\begin{array}{l}\text { Filler content } \\
(\mathrm{wt} \%)\end{array}$ & $\begin{array}{l}\mathrm{NREU} \\
(\mathrm{MJ} / \mathrm{kg})\end{array}$ & $\begin{array}{l}\mathrm{MI}_{\mathrm{Panel}} \\
\left(\mathrm{MPa}^{1 / 3} \cdot 1 \cdot \mathrm{kg}^{-1}\right)\end{array}$ & $\begin{array}{l}\text { Funct-based NREU } \\
\left(\mathrm{MJ} \cdot \mathrm{kg} \cdot \mathrm{MPa}^{-1 / 3} \cdot \mathrm{l}^{-1}\right)\end{array}$ \\
\hline Unfilled & 0 & 56.5 & 4.98 & 11.3 \\
$\mathrm{MMT}^{+} \mathrm{Na}^{+}$ & 3 & 55.0 & 4.95 & 11.1 \\
MMT-Cloisite B $^{-}$ & 3 & 57.1 & 5.79 & 9.86 \\
MMT-Cloisite C & 3 & 56.9 & 5.93 & 9.58 \\
MMT-Cloisite 30B & 3 & 57.1 & 5.14 & 11.1 \\
MMT-Cloisite D & 3 & 56.9 & 5.42 & 10.5 \\
\hline
\end{tabular}

(a)

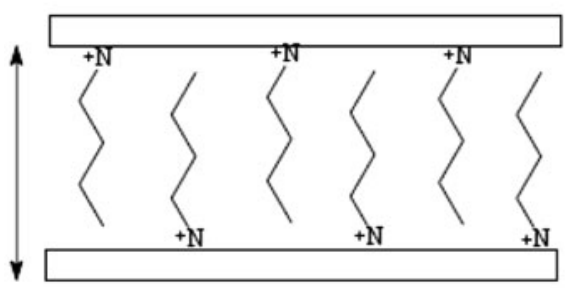

(b)

of Cloisite B (a) and Cloisite C (b) (Malucelli et al. 2007). Reproduced with permission of Elsevier Ltd.

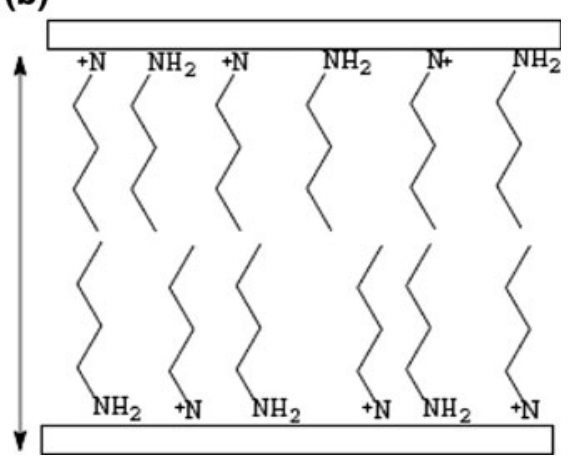

neat polymer resin and nanoclay. Prior to product forming, the masterbatches were diluted and subsequently extruded. The use of a masterbatch thus involves an extra extrusion step, i.e. one to produce the masterbatch and one for dilution and extrusion of the product. This extra extrusion step may also be needed if no grafted polymer is used, i.e. if the polymer resin is directly mixed with the nanoobject. Especially in the laboratory production of nanocomposites an extra extrusion is needed to achieve optimal mixing of the polymer matrix with the nanoobject. However, if a large extruder is used, the mixing can be done in one go together with product forming. Although this study is to a large extent based on laboratory data and lab-scale technology, we try to extrapolate our assumptions to large-scale industrial practice if possible. We therefore base our calculations on one extrusion for both mixing of the nanoobject with the polymer matrix and product forming.

In case we would assume two extrusions, the results change slightly. For the unfilled polymer, only one extrusion is needed, i.e. for product forming. As soon as a filler is used (which represents the much more common case), an extra extrusion for mixing is needed, which increases the environmental impacts and thus the functionality-based NREU. Although for most results presented in this paper the difference is not significant (an increase in filler content still causes an overall decrease in functionality based NREU), we observed a change in case of the MMTCloisite filled LDPE nanocomposites. If a second extrusion were assumed, the addition of a nanoobject would not be beneficial anymore for LDPE-MMT$\mathrm{Na}^{+}$, LDPE-MMT-Cloisite 30B and LDPE-MMTCloisite D, as is shown in Fig. 7.

The NREU for extrusion is assumed to be $7.0 \mathrm{MJ} / \mathrm{kg}$ (Energy Efficiency Enquiries Bureau ETSU 1993; Hischier 2004). For the LDPE nanocomposites, the $\mathrm{MI}_{\text {panel }}$ is between 5 and $6 \mathrm{MPa}^{1 / 3} \cdot \mathrm{dm}^{3} \cdot \mathrm{kg}^{-1}$. This means that an extra extrusion adds $1.2-1.4 \mathrm{MJ} \cdot \mathrm{kg}$. $\mathrm{MPa}^{-1 / 3} \cdot \mathrm{dm}^{-3}$ to the functionality-based NREU. This difference is significant, given the value range of the results. In other cases, the $\mathrm{MI}_{\text {panel }}$ is higher (sometimes $>10 \mathrm{MPa}^{1 / 3} \cdot \mathrm{dm}^{3} \cdot \mathrm{kg}^{-1}$ ) and the resulting contribution of an extra extrusion becomes very small and does not influence the overall results (the slope of the regression line remains negative). 


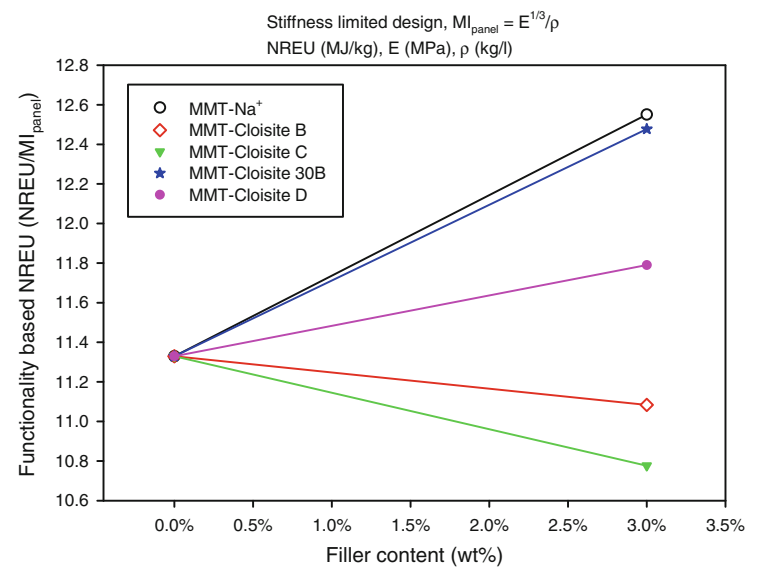

Fig. 7 Functionality-based NREU for LDPE-MMT nanocomposites if two extrusions were assumed

\section{Uncertainties}

The results in this study are subject to uncertainty, mainly for two reasons: (a) data used for the calculation of the environmental impact (NREU) were estimated based on laboratory data or process data obtained from encyclopedias, engineering handbooks and LCA databases. A check with real industrial practice was not always possible; (b) there is a large variety in values for Young's modulus reported by different sources.

The uncertainties regarding the environmental impact of the polymer matrices, nanoobjects, surfactants, compatibilizers, and energy use could mean that the absolute values for NREU of the nanocomposites are higher or lower than presented. It could also influence the steepness of the graphs (e.g. uncertainties in NREU of nanoobjects are more pronounced at higher filler content).

The values for Young's modulus appear to be very much dependent on the study from which they are taken. Various studies report completely different values for similar nanocomposites, but the way the nanocomposites are prepared is also different in each study. The Young's modulus and the way of producing the nanocomposite are related. Moreover, the Young's moduli reported for neat polymers sometimes also differ substantially. For these reasons, when determining the functionality-based environmental impact, the Young's modulus should always be taken from the study on which the environmental assessment is based (different production methods lead to different values for the Young's modulus). The same holds for the tensile strength.

In order to quantify the uncertainties in the analyses of this study, we estimated the uncertainties of different parameters leading to the functionalitybased NREU. We then applied these uncertainties in the calculations, leading to upper and lower values for the functionality-based NREU. Since we studied over 20 different types of nanocomposites, uncertainty analyses of all nanocomposites would be very space consuming. We therefore limited our analyses to two nanocomposites that show particularly good results. In this way, we can present our most optimistic results with the uncertainty of the calculations. The nanocomposites for which we performed an uncertainty analysis are Ep-Si and PU-MMT. In Table 11 an overview is given of the uncertainties we assumed.

Figures 8 and 9 show the results of the uncertainty assessment. Since the slope of the lines is an indication for the improvement of the functionalitybased NREU with increasing filler content, there is also a 'best slope' and a 'worst slope'. The steepest slope ('best slope') is obtained if: (1) all parameters that contribute to a negative slope with increasing filler content (e.g. the amount of polymer matrix ${ }^{7}$ ) are multiplied with the positive uncertainty and (2) if all parameters that contribute to a positive slope with increasing filler content (e.g. the amount of filler) are multiplied with the negative uncertainty. For the flattest slope ('worst slope'), the inverse assumptions have been applied. In Figs. 8 and 9, the dashed lines represent these slopes. The solid lines represent the upper and the lower boundary of the results, if recalculated with the uncertainties assumed in Table 11. The colored line is the original result. In Table 12, the results of the uncertainty analysis are quantified. The absolute improvement is estimated from the lines determined in Figs. 8 and 9.

Table 12 shows that the absolute improvement is highest for Ep-Si and the uncertainties are lower than of PU-MMT. The slope (relative improvement) is steepest for Ep-Si. The slope is flattest for PU-MMT and the

\footnotetext{
$\overline{7 \text { The amount }}$ of polymer matrix decreases with increasing filler content. Therefore, the contribution of the polymer matrix to the total environmental impacts and thus to the functionalitybased NREU decreases with increasing filler content. It therefore contributes to a negative slope of the line.
} 
Table 11 Uncertainties assumed for Ep-Si and PU-MMT

\begin{tabular}{|c|c|c|c|}
\hline \multicolumn{2}{|l|}{ Ep-Si } & \multicolumn{2}{|l|}{ PU-MMT } \\
\hline Parameter & Uncertainty $(\%)$ & Parameter & Uncertainty (\%) \\
\hline Epoxy resin & $+10 /-10$ & PU & $+10 /-10$ \\
\hline Jeffamine & $+20 /-20$ & MMT & $+100 /-50$ \\
\hline TEOS & $+20 /-20$ & Extrusion & $+200 /-50$ \\
\hline Isopropanol & $+10 /-10$ & Electricity vacuum oven & $+200 /-50$ \\
\hline Extrusion & $+200 /-50$ & Young's modulus & $+10 /-10$ \\
\hline Electricity vacuum oven & $+200 /-50$ & Electricity recovery & $+20 /-20$ \\
\hline Electricity conventional oven & $+50 /-50$ & Heat recovery & $+20 /-20$ \\
\hline Young's modulus & $+10 /-10$ & Energy incineration & $+50 /-50$ \\
\hline Electricity recovery & $+20 /-20$ & & \\
\hline Heat recovery & $+20 /-20$ & & \\
\hline Energy incineration & $+250 /-0$ & & \\
\hline
\end{tabular}

Note: Although there is a large variation in Young moduli for the same material among different studies, we assume that the uncertainty for one particular study (the study on which the analysis is based) is only determined by the accuracy of the measuring equipment. Therefore, the uncertainty is assumed to be only $+-10 \%$

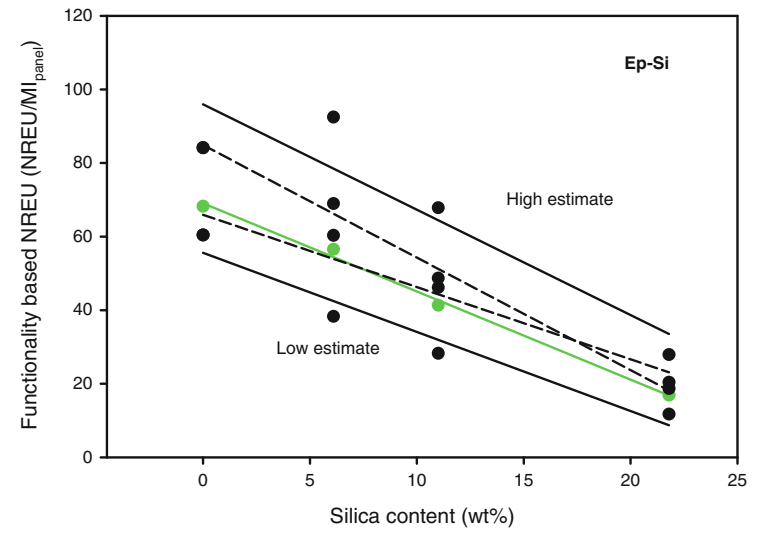

Fig. 8 Uncertainty analysis of Ep-Si

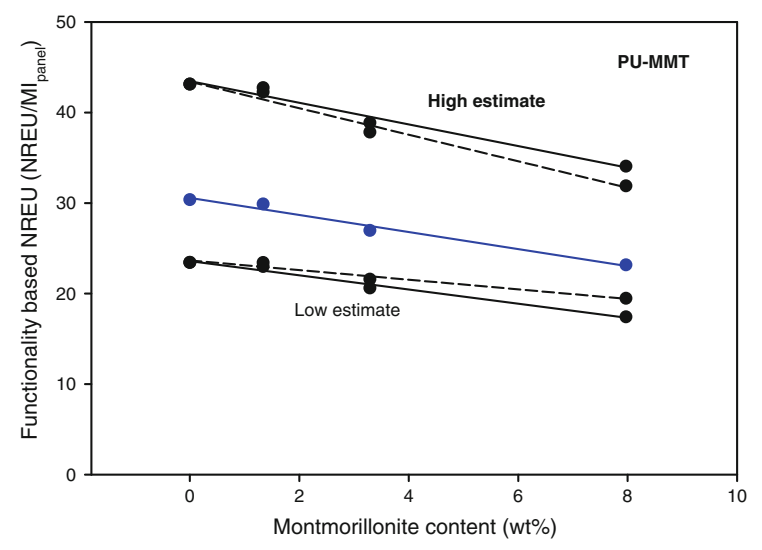

Fig. 9 Uncertainty analysis of PU-MMT uncertainties are highest. The absolute improvement of PU-MMT is much lower than of Ep-Si, but Ep-Si has exceptional improvement compared to all other nanocomposites. As is shown by Figs. $2 \mathrm{a}-\mathrm{d}$ and $3 \mathrm{a}-\mathrm{c}$, the absolute improvement of PU-MMT is comparable to higher than all other nanocomposites. We estimate that the uncertainties for PU-MMT are representative also for the other nanocomposites that have not been covered by this uncertainty analysis, because their production and, hence, the involved parameters are comparable. For the nanocomposites using carbon nanotubes as filler, the uncertainties could be higher, as was revealed in the section "Impact assessment of carbon nanotubes".

The present study focuses on nanocomposites that are used in stationary applications (no energy is accounted for in the use phase). If, however, they were used in mobile applications (such as car panels), then a certain fraction of the energy used in the application (such as fuel in a car) is allocated to the nanocomposite. This would change the results (being to the advantage of the material with the best mechanical properties). For examples, see Roes et al. (2007).

It should also be noted that many more nanocomposites are currently being developed than included in this study. Our aim was to study just a representative subset of nanocomposites. For example, with respect to $\mathrm{PHB}$, research involves the production of $\mathrm{PHB}$ copolymers, which show better mechanical properties than PHB homopolymer (strong and not brittle) (Shen 
Table 12 Quantitative results of the uncertainty analyses

\begin{tabular}{llllll}
\hline Nanocomposite & $\begin{array}{l}\text { Absolute } \\
\text { improvement }\end{array}$ & $\begin{array}{l}\text { Slope } \\
(\% / \%)\end{array}$ & $\begin{array}{l}\text { Slope }\left(\mathrm{MJ} \cdot \mathrm{kg} \cdot \mathrm{MPa}^{-1 /}\right. \\
\left.\mathrm{dm}^{-3} \cdot \%^{-1}\right)\end{array}$ & $\begin{array}{l}\text { Uncertainty of the slope } \\
\left(\mathrm{MJ} \cdot \mathrm{kg} \cdot \mathrm{MPa}^{-1 / 3} \cdot \mathrm{dm}^{-3} \cdot \%^{-1}\right)\end{array}$ & $\begin{array}{l}\text { Uncertainty of the } \\
\text { slope }(\%)\end{array}$ \\
\hline Ep-Si & $65-85$ & -3.5 & -2.4 & $+0.4 /-0.7$ & $+18 /-28$ \\
PU-MMT & $18-27$ & -3.0 & -0.9 & $+0.4 /-0.5$ & $+45 /-55$ \\
\hline
\end{tabular}

${ }^{a}$ For each of the lines in Figs. 8 and 9 the absolute improvement was determined by calculating the difference in functionality based NREU at the end of the lines and the beginning of the lines. This difference was expressed as the percentage improvement compared to the initial value (at $0 \%$ filler). Since for each line the absolute improvement is different, this explains the ranges for absolute improvement

b The slope is determined (1) as the percentage improvement per percentage increase of filler (\%/\%), (2) as the absolute improvement per percentage increase of filler $\left(\mathrm{MJ} \cdot \mathrm{kg} \cdot \mathrm{MPa}^{-1 / 3} \cdot \mathrm{dm}^{-3} \cdot \%^{-1}\right.$ )

et al., forthcoming). The reinforcement of these PHB co-polymers with nanoobjects is currently being studied (e.g., Zhang et al. 2007). Therefore, if research continues, it is recommended that the present study is extended when new nanocomposites have been developed with improved technology.

\section{Conclusions}

In the present study, we developed and applied an indicator that addresses both the environmental impacts of nanocomposites (represented by the NREU) and its material properties. With the help of this indicator - the 'functionality-based NREU' - we were able to assess the potential benefits of using nanoobjects to reinforce polymers compared to unfilled (neat) polymers or conventionally filled polymers. The main question was whether the addition of nanoobjects to a polymer matrix increases the mechanical properties to the extent that a possible increase in environmental impacts caused by the nanoobjects is compensated for or, ideally, overcompensated. To this end, we assessed the NREU of 23 different nanocomposites and three conventional composites. The environmental impacts of organophilic montmorillonite, silica, and carbon nanotubes (all fillers used in the nanocomposites) were determined separately.

The conclusion is that the addition of nanoobjects to polymers can have a positive effect on the functionality-based NREU; we found that this was the case for PC-MMT, LLDPE-MMT, PTT-MMT, HDPE-MMT, TPS-MMT, EP-Si, PCL-MMT, PUMMT, XLDPE-MMT, LDPE-MMT, Nylon 66-MMT, PET-MMT, Nylon 6-MMT, PLA-Si, PMMAMWNT, NR-MMT, EPDM-SWNT and PVC-MMT.
In the best cases, the improvement is $3-6 \%$ per percent increase of filler ${ }^{8}$ (the average of the nanocomposites with a negative slope is $2.4 \%$ improvement per percent increase of filler).

The addition of organophilic montmorillonite to natural rubber results in much lower functionalitybased NREU compared to unfilled natural rubber or natural rubber filled with unmodified montmorillonite or carbon black. In other cases, however, there were no benefits. For example, the use of organophilic montmorillonite in PHB nanocomposites resulted in higher functionality-based NREU compared to unfilled PHB or PHB filled with sugarcane bagasse. Furthermore, the use of organophilic montmorillonite in PP-MMT and PLA-MMT, the use of $\mathrm{CaCO}_{3}$ in PVC-CaCO 3 and the use of carbon nanotubes in PSSWNT did not result in lower functionality-based environmental impacts. It should, however, be emphasized that the uncertainties are substantial. In the case of PU-MMT, for which we assume the uncertainties to be comparable to most of the other nanocomposites, the relative improvement (slope of the line) is subject to a maximal uncertainty of $+45 \% /-55 \%$.

The data for all present analyses originate from current (often early lab-scale) technology. This means that material properties might still be inferior to what will be feasible when technology matures. Since there is still large variation in mechanical properties among different studies, further research is urgently required in order to get a better grip on the mechanical properties of nanocomposites and their determining factors.

\footnotetext{
$\overline{8}$ Best cases (\% improvement of functionality-based NREU per $\%$ increase in filler): Ep-Si (3.4\%/\%), TPS-MMT (3.5\%/ $\%)$, HDPE-MMT (3.6\%/\%), EPDM-SWNT $(5.4 \% / \%)$ and LDPE-MMT $(5.7 \% / \%)$.
} 
If also the environmental impacts of the preparation of the nanocomposites can be reduced (e.g. by being more energy-efficient), the use of nanoobjects as filler might become beneficial also for nanocomposites which were found to be disadvantageous in this study.

Based on our results, we consider overall savings of $20 \%$ for NREU to be feasible for nanocomposites compared to unfilled polymers. It is recommended to further exploit this potential in parallel to investigations on health and safety which have not been studied in this paper.

Acknowledgments This study has been supported by the EUNetwork of Excellence NANOFUN-POLY "Nanostructured and Functional Polymer-based Materials and Nanocomposites" (www.nanofun-poly.org). We also thank Dr. Herbert Barthel (Wacker Chemie AG), Prof. Dr. Ray Baughman (Nanotech Institute, Technical University of Texas), Dimitris Kastanis MSc. and Dr. Konstantinos Dassios (FORTH/ICE-HT, Greece), Prof. Ramani Narayan (Michigan State University, USA), Dr. Peter Krüger (Bayer Material Science AG) and Dr. Miguel Angel López-Manchado (Institute for Polymer Science and Technology (CSIC), Madrid) for their helpfulness in providing us with technical information.

\section{References}

Ahmadi SJ, Huang YD, Li W (2004) Synthetic routes, properties and future applications of polymer-layered silicate nanocomposites. J Mater Sci 39(6):1919-1925

Arroyo M, López-Manchado MA, Herrero B (2003) Organomontmorillonite as substitute of carbon black in natural rubber compounds. Polymer 44(8):2447-2453. doi:10.1016/ S0032-3861(03)00090-9

Ashby MF (2005) Materials selection in mechanical design, 3rd edn. Elsevier Butterworth-Heinemann, Burlington

Avella M, de Vlieger JJ, Errico ME, Fischer S, Vacca P, Volpe MG (2005) Biodegradable starch/clay nanocomposite films for food packaging applications. Food Chem 93(3):467-474. doi:10.1016/j.foodchem.2004.10.024

Chavarria F, Paul DR (2004) Comparison of nanocomposites based on nylon 6 and nylon 66. Polymer 45(25):85018515. doi:10.1016/j.polymer.2004.09.074

Chavarria F, Paul DR (2006) Morphology and properties of thermoplastic polyurethane nanocomposites: effect of organoclay structure. Polymer 47(22):7760-7773. doi:10.1016/ j.polymer.2006.08.067

Drown EK, Mohanty AK, Parulekar Y, Hasija D, Harte BR, Misra M, Kurian JV (2007) The surface characteristics of organoclays and their effect on the properties of poly(trimethylene terephthalate) nanocomposites. Compos Sci Technol 67(15-16):3168-3175. doi:10.1016/j.compsci tech.2007.04.011

Ecoinvent (2009) Ecoinvent database. Available online at www.ecoinvent.ch
Energy Efficiency Enquiries Bureau ETSU (1993) Guide 31, the moulding of thermo-plastic containers by the extrusion-blow moulding process. Harwell, Oxfordshire, p 11

European Commission (2007) Integrated pollution prevention and control (IPPC). Reference document on best available techniques for the manufacture of large volume inorganic chemicals-solids and others industry, Chap. 5, Synthetic amorphous silica. Available online at http://eippcb.jrc.ec. europa.eu/pages/FActivities.htm

Freudenstein M (2007) Low-density polyethylene (PE-LD/ LLD). Kunststoffe international, vol 97, Carl Hanser Verlag, München. www.kunststoffe-international.com

Frischknecht R, Jungbluth N, Althaus H-J, Doka G, Dones R, Hischier R, Hellweg S, Humbert S, Margni M, Nemecek T, Spielmann M (2004) Implementation of life cycle impact assessment methods. Ecoinvent report no. 3, Swiss Centre for Life Cycle Inventories, Dübendorf, Switzerland

Halimi C, Gerard JF (2008) Etude du nanocomposite polyacide lactique/silice. Projet de Fin d'etudes, année scolaire 2007-2008. Institute National des Sciences Appliquées de Lyon

Healy ML, Dahlben LJ, Isaacs JA (2008) Environmental assessment of single-walled carbon nanotube processes. J Ind Ecol 12(3):376-393. doi:10.1111/j.1530-9290.2008. 00058.x

Hischier R (2004) Life cycle inventories of packagings and graphical papers. Ecoinvent report no. 11, Swiss Centre for Life Cycle Inventories, Dübendorf, Switzerland. Online version at www.ecoinvent.ch

Hotta S, Paul DR (2004) Nanocomposites formed from linear lo density polyethylene and organoclays. Polymer 45(22): 7639-7654. doi:10.1016/j.polymer.2004.08.059

Huijbrechts MAJ, Rombouts LJA, Hellweg S, Frischknecht R, Hendriks AJ, van de Meent D, Ragas AMJ, Reijnders L (2006) Is cumulative fossil energy demand a useful indicator for the environmental performance of products? Environ Sci Technol 40(3):641-648. doi:10.1021/es051689q

Intergovernmental Panel on Climate Change (IPCC) (2007) Climate change 2007. IPCC fourth assessment report. The physical science basis. Cambridge University Press, New York. Available online at http://www.ipcc.ch/ipccreports/ ar4-wg1.htm

International Standards Organization (2000) Environmental management-life cycle assessment-examples of application of ISO 14041 to goal and scope definition and inventory analysis. ISO/TR 14049:2000(E)

International Standards Organisation (2006a) Environmental management-life cycle assessment-principles and framework. ISO/FDIS 14040:2006(E). Downloadable from www.iso.org

International Standards Organisation (2006b) Environmental management-Life cycle assessment-requirements and guidelines. ISO/FDIS 14044:2006(E). Downloadable from www.iso.org

Jiang L, Zhang J, Wolcott MP (2007) Comparison of polylactide/nano-sized calcium carbonate and polylactide/ montmorillonite composites: reinforcing effects and toughening mechanisms. Polymer 48(26):7632-7644. doi: 10.1016/j.polymer.2007.11.001

Joshi S (2008) Can nanotechnology improve the sustainability of biobased products? The case of layered silicate 
biopolymer nanocomposites. J Ind Ecol 12(3):474-489. doi:10.111/j.1530-9290.2008.00039.x

Kirk-Othmer (1998) Encyclopedia of chemical technology, 4th edn. Wiley, New York

Kushnir D, Sandén BA (2008) Energy requirements of carbon nanoparticle production. J Ind Ecol 12(3):360-375. doi: 10.1111/j.1530-9290.2008.00057.x

Lee W-J, Lee S-E, Kim C-G (2006) The mechanical properties of MWNT/PMMA nanocomposites fabricated by modified injection molding. Compos Struct 76(4):406-410. doi:10.1016/j.compstruct.2005.11.008

Luduena LN, Alvarez VA, Vazquez A (2007) Processing and microstructure of PCL/clay nanocomposites. Mater Sci Eng A 460-461:121-129. doi:10.1016/j.msea.2007.01.104

Malucelli G, Ronchetti S, Lak N, Priola A, Tzankova NT, La Mantia FP (2007) Intercalation effects in LDPE/o-montmorillonites nanocomposites. Eur Polym J 43(2):328-335. doi:10.1016/j.eurpolymj.2006.11.024

Matějka L, Dukh O, Kolařík J (2000) Reinforcement of crosslinked rubbery epoxies by in-situ formed silica. Polymer 41(4):1449-1459. doi:10.1016/S0032-3861(99) 00317-1

Matweb (2008). Matweb-material property data. Available online at www.Matweb.com. Accessed 17 Jan 2008

Morawiec J, Pawlak A, Slouf M, Galeski A, Piorkowska E, Krasnikowa N (2005) Preparation and properties of compatibilized LDPE/organo-modified montmorillonite nanocomposites. Eur Polym J 41(5):1115-1122. doi:10. 1016/j.eurpolymj.2004.11.011

Nanocor (2008) Nanoclay structures. Available online at http:// www.nanocor.com/nano_struct.asp. Accessed 5 Aug 2008

Nayak RR, Lee KY, Shanmugharaj AM, Ryu SH (2007) Synthesis and characterization of styrene grafted carbon nanotube and its polystyrene nanocomposite. Eur Polym J 43(12):4916-4923. doi:10.1016/j.eurpolymj.2007.04.012

Patterson RE (1998) Silica (introduction). In: Kirk-Othmer, Encyclopedia of chemical technology, 4th edn. Wiley, New York

Pietrini M, Roes AL, Patel MK, Chiellini E (2007) Comparative life cycle studies on poly(3-hydroxybutyrate)-based composites as potential replacement for conventional petrochemical plastics. Biomacromolecules 8(7):2210 2218. doi:10.1021/bm0700892S1525-7797(07)00089-X

PlasticsEurope (2009) PlasticsEurope ecoprofiles. Available online at www.plasticseurope.org

PRé Consultants (2006) SimaPro 7, Multi User 7.0.1

Qiu W, Mai K, Zeng H (1999) Effect of macromolecular coupling agent on the property of PP/GF composites. J Appl Polym Sci 71(10):1537-1542. doi:10.1002/(SICI) 1097-4628(19990307)71:10<1537:AID-APP1>3.0.CO;2-E

Reimann DO (2006) CEWEP energy report-status 2001-2004: results of specific data for energy, efficiency rates and coefficients, Plant efficiency factors and NCV of 97 European W-t-E plants and determination of the main energy results, CEWEP, Bamberg, Germany, October 2005, update July 2006. Available online at http://www. cewep.com/storage/med/media/statements/106_11_07_ 06_CEWP-Report_Final_Version.pdf?fCMS $=94923 \overline{5}$ 9815c9d578a7fbb6af355da3b9

Rezanejad S, Mehrdad K (2007) Shape memory and mechanical properties of cross-linked polyethylene/clay nanocomposites. Eur Polym J 43(7):2856-2865. doi: 10.1016/j.eurpolymj.2007.04.031

Roes AL, Marsili E, Nieuwlaar E, Patel MK (2007) Environmental and cost assessment of a polypropylene nanocomposite. J Polym Env 15(3):212-226. doi:10.1007/ s10924-007-0064-5

Shen L, Haufe J, Patel MK. Emerging bio-based plastics: product overview and market projection. Group Science, Technology and Society (STS), Copernicus Institute for Sustainable Development and Innovation, Utrecht University (forthcoming)

Svoboda P, Zeng C, Wang H, Lee LJ, Tomasko DL (2002) Morphology and mechanical properties of polypropylene/ organoclay nanocomposites. J Appl Polym Sci 85(7): 1562-1570. doi:10.1002/app.10789

Tjong SC, Bao SP (2007) Fracture toughness of high density polyethylene/SEBS-g-MA/montmorillonite nanocomposites. Comp Sci Technol 67(2):314-323. doi:10.1016/ j.compscitech.2006.08.006

Ullmann's (2007) Encyclopedia of industrial chemistry. WileyVCH Verlag GmbH \& Co. KGaA

Wan C, Qiao X, Zhang Y, Zhang Y (2003) Effect of different clay treatment on morphology and mechanical properties of PVC-clay nanocomposites. Polym Test 22(4):453-461. doi:10.1016/S0142-9418(02)00126-5

Wang Y, Gao J, Ma Y, Agarwal US (2006) Study on mechanical properties, thermalstability and crystallization behavior of PET/MMT nanocomposites. Compos Part B 37(6):399-407. doi:10.1016/j.compositesb.2006.02.014

West RD, Malhotra VM (2006) Rupture of nanoparticle agglomerates and formulation of $\mathrm{Al}_{2} \mathrm{O}_{3}$-epoxy nanocomposites using ultrasonic cavitation approach: effects on the structural and mechanical properties. Polym Eng Sci 46(4):426-430. doi:10.1002/pen.20513

Wikipedia (2007) The free encyclopedia. Available online at http://en.wikipedia.org

Yoon PJ, Hunter DL, Paul DR (2003) Polycarbonate nanocomposites: part 2. Degradation and color formation. Polymer 44(18):5341-5354. doi:10.1016/S0032-3861(03) 00523-8

Zhang J, Jiang DD, Wilkie CA (2005a) Polyethylene and polypropylene nanocomposites based upon an oligomerically modified clay. Thermochim Acta 430(1-2):107-113. doi:10.1016/j.tca.2005.01.028

Zhang L, Chen X, Li C (2005b) Mechanical properties of PVC/ nano- $\mathrm{CaCO}_{3}$ composites. J Mater Sci 40(8):2097-2098. doi:10.1007/s10853-005-1244-0

Zhang J, Jiang DD, Wilkie CA (2006a) Polyethylene and polypropylene nanocomposites based on a three component oligomerically modified clay. Polym Degrad Stabil 91(4): 641-648. doi:10.1016/j.polymdegradstab.2005.02.004

Zhang J, Jiang DD, Wilkie CA (2006b) Thermal and flame properties of polyethylene and polypropylene nanocomposites based on an oligomerically-modified clay. Polym Degrad Stabil 91(2):298-304. doi:10.1016/j.polymdegrad stab.2005.05.006

Zhang X, Lin G, Abou-Hussein R, Hassan MK, Noda I, Mark JE (2007) Some novel layered-silicate nanocomposites based on a biodegradable hydroxybutyrate copolymer. Eur Polym J 43(8):3128-3135. doi:10.1016/j.eurpolymj.2007.04.043 